\title{
THE SURGICAL TREATMENT OF FLATULENT COLIC IN THE HORSEx
}

\author{
By Thomas Campbell, F.R.C.V.S., Kirkcudbright.
}

THE success attending my mode of treating this malady within the last few years has been so complete, that I consider it my duty to lay it before the profession through the columns of your Fournal.

Tympanites may appear as a complication in the course of various affections, but we country practitioners find it, as a general rule, due to dietetic causes. It is particularly common in breeding districts such as this, where there are studs of valuable Clydesdales bred and brought up for show purposes. Such animals are generally very highly fed, the diet being to a very large extent of cooked food, in a highly fermentable condition.

My experience has been that in nine cases out of ten, if you await the action of a cathartic or of medicines given with a view to the neutralisation of gases, long ere such action takes place your patient will collapse, dying of asphyxia.

Some years ago I operated on three or four cases with the ordinary trocar (made for the purpose by Arnold \& Sons, London); but, although the operation gave relief at the time, the cases terminated fatally, and on post-mortem examination $I$ found in two cases a transverse rupture of the wall of the colon. From the nature of the lesions in the last case I operated on with this form of trocar, I came to the conclusion that the instrument was too large. The instrument I now use is similar to a large aspirator needle of the size and shape shown in the annexed figure. It has no handle except a flat knob on the head of the trocar, and it can be carried in an ordinary pocket-case of instruments.

The mode of operating is as follows:-Puncture the intestine at the most prominent part of the right upper flank, pushing the instrument straight in up to the neck, then withdraw the trocar and leave the canula in, until gas ceases to come away. I have always found that as soon as the tympany is relieved the intestine moves forward, taking with it the point of the canula. If the animal is not entirely relieved, re-enter the trocar into the canula, pull the instrument nearly out, and again send it straight into a new part of the intestine. If necessary, leave the instrument in for half an hour, and by that time the patient will be completely relieved. It is seldom necessary to operate a second time, but if the animal again becomes uneasy and tympanitic,

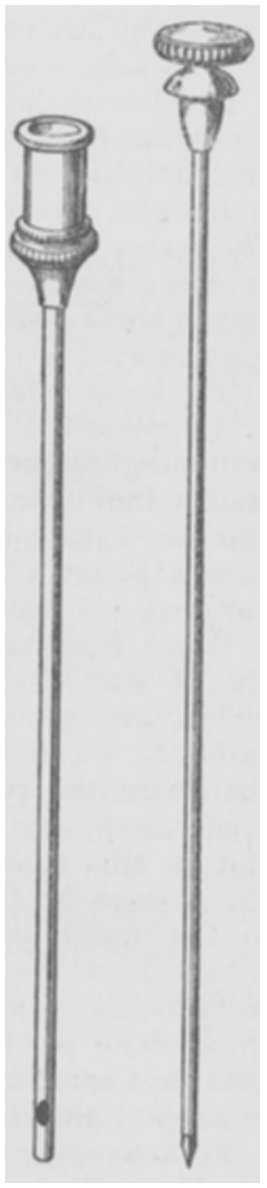
puncture again at once in the manner described.

No practitioner need be in the least degree apprehensive of untoward 
results in operating in this manner, as I have so done in nearly a score of cases without the slightest evil after effect.

As an illustration I may mention the following case:-One of my driving horses got loose through the night, and gorged himself with corn beans, and bran. The groom reported the occurrence to me in the morning, and when I went down to the stable, I found the horse standing with his head dependent, and appearing very uneasy. I ordered a physic ball, to be followed in an hour with a drench of carbonate of ammonia, turpentine, and ether.

The horse must have broken loose and gorged himself very early in the evening, for when I again examined him, about Io A.M., I found him rapidly becoming tympanitic. In an hour I had to operate in order to save his life, and between I I A.M. and 8 P.M. I was obliged to puncture him three times. The physic did not operate till the following day, and had it not been that the horse was rather severely purged by the cathartic he would have been at his work in two days. However, in a week he was all right and at work.

\section{EDITORIAL ARTICLES*}

\section{THE NATURE OF IMMUNITY AND PROTECTION IN THE CASE OF INFECTIOUS DISEASES.}

VARIOUS theories have been framed to account for the observed fact, that in the case of certain specific (contagious or infectious) diseases immunity more or less complete is conferred by the first attack. Under one view, the immunity is explained by supposing that something absolutely necessary for the growth and multiplication of the specific germ-something standing to the germ in the relation of a food material-is entirely consumed during the first attack, and that material not being reformed, the organism of the same individual cannot again serve as a medium for the development of that particular germ.

Another theory ascribes the immunity to a particular product generated in the body of the animal during the first attack, this material being antidotal to the specific germ. The production of this material, it is supposed, not only accounts for the subsidence of the first attack after a tolerably definite period, but, since the material is for a longer or shorter period retained within the system, it renders the individual proof for a time against the development of any germs of the same nature.

A third hypothesis may be stated shortly thus:-When spontaneous recovery takes place from a first attack, it is due to the fact that in the battle waged between the disease germ and the cells of the animal body (the white cells of the blood chiefly) the latter have 